\title{
ANALISIS PENDEKATAN TEKNOLOGI E-BISNIS STUDI KASUS TOKOPEDIA
}

\author{
Rudi Setiawan \\ 165100105 \\ Fakultas Komputer \\ rudisetiawan.student@umitra.ac.id
}

\begin{abstract}
Tokopedia merupakan salah satu startup di Indonesia. Berdiri sejak 2007 dan di release ke publik pada 17 Agustus 2009. Tokopedia merupakan salah satu startup pertama di Indonesia. Tokopedia didirikan oleh pemuda Indonesia yaitu Williiam Tanuwijaya bersama rekannya Leontinus Alpha Edison.
\end{abstract}

Tokopedia merupakan satu dari empat Unicorn baru di dunia asal Indonesia. Unicorn adalah startup yang memiliki nilai valuasi USD 1 Miliar lebih. Ini semua tak lepas dari suntikan dana dari perusahaan-perusahaan besar luar negeri salah satunya adalah perusahaan e-commerce terbesar dari China yaitu Alibaba.

Tokopedia merupakan situs beli online terbesar di Indonesia, menjadi nomer satu di Indonesia mengalahkan marketplace lainnya. Ini semua tak lepas dari fitur-fitur yang diberikan oleh tokopedia dan hobi baru masyarakat Indonesia yaitu berbelanja online.

Kata Kunci : Unicorn \& Startup terbesar di Indonesia

\section{A. PENDAhuluan}

Berbelanja online sudah menjadi kebiasaan masyarakat Indonesia saat ini. Tidak heran jika saat ini banyak sekali marketplace yang bermunculan Sejak didirikan pada tahun
2009, Tokopedia sekarang menjelma sebagai marketplace terbesar di Indonesia. Seorang pemuda bernama Williiam Tanuwijaya adalah sosok pendiri marketplace terbesar ini, bersama rekannya 
Leontinus Alpha Edison. Ia melalui banyak perjuangan berat bersama rekannya dalam membangun tokopedia hingga menjadi besar seperti sekarang.

Ide mendirikan startup tokopedia muncul ketika ia menjadi moderator dalam forum online Kafegaul yang mempunyai fasilitas jua beli. Dari situ ia kemudian mulai terinspirasi untuk menciptakan startup baru yang kemudian ia namakan dengan tokopedia. Pada tahun 2007, dari idenya ia kemudian membangun Tokopedia. Ia mengajak temannya untuk mendirikan Tokopedia sebuah startup jual beli online, yang menghubungkan antara penjual dan pembeli diseluruh Indonesia dengan biaya gratis. Tokopedia resmi diluncurkan ke publik pada 17 Agustus 2009 di bawah naungan PT Tokopedia yang didirikan oleh William Tanuwijaya dan Leontinus Alpha Edison pada 6 Februari 2009. Sejak resmi diluncurkan, PT Tokopedia berhasil menjadi salah satu ecommerce Indonesia dengan pertumbuhan yang sangat pesat. PT Tokopedia mendapatkan pendanaan awal dari PT Indonusa Dwitama pada tahun 2009. Pada tahun-tahun berikutnya, Tokopedia kembali mendapat suntikan dana dari pemodal ventura global seperti East Ventures, Cyber Agent Ventures, Netprice, dan SoftBank Ventures Korea. Pada Oktober 2014, Tokopedia menjadi perusahaan teknologi pertama di Asia Tenggara yang menerima investasi sebesar USD 100 juta atau sekitar Rp 1,2 triliun dari Sequoia Capital dan SoftBank Internet and Media Inc (SIMI). Pada April 2016, Tokopedia kembali dikabarkan mendapatkan investasi sebesar USD 147 juta atau sekitar Rp 1,9 triliun. Pada bulan Agustus 2017, Tokopedia menerima investasi sebesar USD 1,1 milyar dari Alibaba. Dikabarkan bahwa keputusan ini dilakukan agar Alibaba dapat semakin memperluas jaringannya di Indonesia dan Asia Tenggara setelah sebelumnya membeli saham Lazada. Berkat peranannya dalam mengembangkan bisnis daring di Indonesia, Tokopedia berhasil meraih penghargaan Marketeers of the Year 2014 untuk sektor e-Commerce pada acara Markplus Conference 2015 yang digelar oleh Markplus Inc. pada tanggal 11 Desember 2014. Pada 12 Mei 2016, Tokopedia terpilih sebagai Best Company in Consumer Industry dari Indonesia Digital Economy Award 2016. Pada tahun 2018, Tokopedia kembali meraih beberapa penghargaan. Mei lalu lalu aplikasi Tokopedia berhasil memuncaki Apple Store mengalahkan Facebook, WhatsApp, dan Instagram. Sementara di Android, Tokopedia juga berhasil menjadi \#3 Top Chart di Google Play mengalahkan Facebook dan Instagram. Pada Desember 2018 Tokopedia terpilih sebagai aplikasi terbaik pilihan masyarakat di Google Play. Melesatnya tokopedia ke jajaran marketplace terbesar di Indonesia membuat nama William Tanuwijaya masuk sebagai salah satu orang terkaya di Indonesia.

\section{B. PEMBAHASAN / STUDI KASUS}

Perkembangan Tokopedia menjadi perusahaan yang besar yang diperhitungkan. Dari awal tokopedia ini berdiri sejak 2007 dan baru terealisasi pada tahun 2009 , perjalanan 
tokopedia pada tahun pertama peluncurannya bisa dibilang cukup baik dan sangat membanggakan. Hal itu terbukti dengan adanya perolehan penghargaan dari Bubu Award sebagai salah satu Bisnis Startup E-commerce terbaik di Indonesia. Seiring berjalannya waktu selama setahun dari Tokopedia didirikan, Tokopedia mendapat antusias dari berbagai kalangan merchant dan customer. Pada awal bulan berdirinya Tokopedia berhasil menggandeng 509 merchants dengan 4560 members. Jumlah tersebut terus bertambah hingga pada ulang tahun pertamanya pada tanggal 17 Agustus 2010 Tokopedia menggaet 4659 merchants dengan 44785 members. Suatu pencapaian yang luar biasa selama setahun tersebut. Dari jumlah transaksi awal bulan berdirinya hanya Rp 33 juta melejit hingga Rp 5,954 milyar pada ulang tahun pertama 17 Agustus 2010. Sekaligus pada ulang tahun pertama Tokopedia, Tokopedia melepas tag beta version yang mengindikasikan bahwa Tokopedia siap untuk melayani merchant dan customer yang bertransaksi pada sistem mereka. Limit harga produk dinaikkan senilai $\mathrm{Rp} 25$ juta yang sebelumnya hanya mencapai Rp 9,99 juta. Begitupun dengan limit transaksi pada market place Tokopedia naik menjadi $\mathrm{Rp} 40$ juta dari $\mathrm{Rp} 15$ juta. Setelah ulang tahun yang pertamanya, perusahaan yang digawangi oleh 2 orang hebat ini terus melakukan improvisasi pada fitur mereka, kecepatan akses serta terus memperbaiki layanan customer care. Tokopedia juga menggandeng bank Mandiri dan bank BCA untuk memberikan keamanan transaksi antara merchant dan customer.
Pembayaran dapat dilakukan dengan transfer ke salah satu rekening Tokopedia, Mandiri ClickPay, Mandiri E-cash, dan BCA KlikPay. East Ventures (2010), CyberAgent Venture (2011), Beenos (212) serta Softbank (2013), Sequoia, dll. Saat ini Tokopedia juga melebarkan sayapnya untuk merintis aplikasi mobile untuk sistem operasi Android. Bahkan Tokopedia juga telah mempunyai rencana untuk membuat aplikasi untuk para pengguna sistem operaso iOS dan juga versi tablet. Pastinya perjalanan dari bisnis William Tanuwijaya akan memberikan banyak inspirasi bagi kita untuk meraih kesukesan yang sama. Memang hal itu tak akan mudah, untuk itu mulailah belajar dari sekarang dan tak mudah puas dengan segala hal yang kita capai. Karena kepuasan ini hanya akan membuat kita berhenti untuk berkembang dan tentunya belajar segela sesuatu yang baru. Bersamaan dengan ulang tahunnya, 17 Agustus 2017 lalu, Tokopedia juga mengumumkan telah meraih komitmen investasi senilai US $\$ 1,1$ miliar dari Grup Alibaba. Investasi ini akan menjadikan Grup Alibaba sebagai pemegang saham minoritas di Tokopedia dan tidak memengaruhi kebijakan Tokopedia sebagai perusahaa independen. Kini, ada lebih 150 juta kunjungan setiap bulan ke Tokopedia. Berdasarkan data terakhir pada 2017, lebih dari $80 \%$ transaksi dilakukan melalui mobile app. Berdasarkan laporan AppAnnie pada 2017, Tokopedia adalah shopping app paling top di Indonesia. Tokopedia juga menjadi situs e-commrce Indonesia nomor wahid. Investasi dari Grup Alibaba dimanfaatkan Tokopedia agar dapat lebih jauh lagi mencapai 
misinya untuk pemerataan ekonomi secara digital di seluruh Indonesia. Salah satunya adalah dengan membangun pusat inovasi terbaik di Indonesia untuk mengembangkan talenta dan sumber daya manusia, mengakselerasi inovasi-inovasi baru di Indonesia, serta mewujudkan misi Tokopedia. Misi Tokopedia sejalan dengan misi Presiden Jokowi dalam mewujudkan Indonesia sebagai kekuatan ekonomi digital terbesar di Asia Tenggara pada tahun 2020, dengan target potensi pasar sebesar US\$130 miliar. Hal ini sejalan dengan berbagai program pemerintah, seperti program Ekonomi Inklusif yang digagas oleh Kementerian Koordinasi Bidang Perekonomian dan Program 8 Juta UMKM Go Online yang digalakkan oleh Kominfo RI. Bagi William, membangun Tokopedia layaknya membangun sebuah kota. Ada konsep kolaborasi di dalamnya. Tokopedia membutuhkan mitra-mitra strategis yang juga memiliki semangat sama dalam mewujudkan pemerataan ekonomi secara digital. Tokopedia hadir sebagai e-commerce baru yang inovatif dan mengusung konsep kumpulan berbagai toko online di Indonesia. Segala aktifitas jual beli dan proses transaksi akan dijamin keamananya melalui perantaraan tokopedia. Konsep ini diharapkan dapat mewujudkan suatu bentuk mall online yang memprakarsai dan mengkoordinasi sejumlah transaksi ecommerce. Fitur-Fitur Yang Tersedia di Tokopedia, antara lain:

- Gold Merchant, Banyak sekali fiturfitur unggulan yang terdapat di dalamnya dan pastinya akan menguntungkanmu. Gold Badge yang muncul di halaman toko dan produk yang akan menarik perhatian calon pembeli, TopAds yang pastinya akan sangat membantu kamu untuk promosi, Statistik Toko untuk memantau performa tokomu, 1 Slot Admin Toko Gratis yang bisa kamu gunakan untuk menambah admin toko. Semua itu bisa langsung kamu rasakan dengan berlangganan Gold Merchant . - Free Returns, Fitur ini memungkinkan pembeli untuk meretur produk secara gratis jika tidak sesuai atau tidak cocok dengan catatan produk masih dalam kondisi layak dijual. Dengan memfasilitasi produkmu menggunakan Free Returns ini, tentunya tokomu akan lebih terlihat terpercaya di mata calon pembeli. Untuk penjual yang ingin menggunakan fitur ini, kamu tidak akan dikenakan biaya sama sekali sampai waktu yang ditentukan.

- Stock Management, Fitur ini akan memudahkanmu melihat sisa produk yang ada di toko, sehingga kamu tidak perlu lagi repot menghitung sisa produk setiap kali ada pesanan masuk. Dan yang paling penting, fitur ini bisa meminimalisir cancellation rate di tokomu karena stok produk yang habis akan otomatis masuk ke Stok Kosong, sehingga tidak dapat dipesan pembeli. -Mitra Toppers, Mitra Toppers adalah program kerjasama Tokopedia dengan mitra penyedia pinjaman yang memudahkan kamu untuk mendapatkan pinjaman modal usaha. Tokopedia bekerja sama dengan beberapa mitra penyedia pinjaman yang bisa kamu pilih seperti : BRI, UOB, Amar Bank, DBS, Bank Sampoerna, Taralite, hingga Modalku. Modal yang kamu dapatkan bisa untuk memenuhi berbagai kebutuhan bisnis onlinemu, mulai dari menambah stok 
dan varian produk, menambah tenaga pekerjaan, sampai mendaftarkan merek dagang.

- Pre Order, Dengan menggunakan fitur Pre Order, kamu bisa mendapatkan waktu tambahan untuk memproses pesanan sampai 30 hari. Fitur ini juga bisa kamu manfaatkan jika menerima pesanan dalam jumlah banyak. Jadi jika stok pesanan tidak mencukupi, produk tidak perlu digudangkan, kamu hanya cukup mengubahnya menjadi produk Pre Order. Dengan begitu, produk tersebut tetap bisa dilihat dan dibeli namun dengan waktu proses yang lebih lama.

- Instoped, Fitur yang bisa mengupload produk langsung ke Instagram, tidak Cuma 1 atau 2 produk saja bahkan bisa meng-upload hingga 20 produk sekaligus.

- User Management, Kamu bisa menambah beberapa orang (maksimal 10 orang) untuk bantu mengelola tokomu di Tokopedia. Tambahan admin ini dibagi menjadi 3 antara lain Admin Toko, Admin Transaksi, dan Admin pesan.

\section{ID SECURITY QWTD4452377-ASP-5244107}

\section{KESIMPULAN}

Awal ide muncul untuk mendirikan tokopedia adalah pada tahun 2007. Tokopedia merupakan startup kreasi anak bangsa. Seorang pemuda bernama Williiam Tanuwijaya adalah sosok pendiri marketplace terbesar ini, bersama rekannya Leontinus Alpha Edison. Tokopedia berhasil diluncurkan ke publik pada tanggal 17 Agustus 2009 bertepatan dengan dirgahayu Republik Indonesia yang ke 64 di bawah naungan PT Tokopedia. Saat ini Tokopedia menjadi marketplace terbesar di Indonesia. Kesuksesan Tokopedia saat ini dikarenakan banyaknya investasi atau suntikan dana dari perusahaanperusaahaan baik dari dalam maupun luar negeri dari 2009 sampai terakhir pada bulan agustus 2017 Tokopedia mendapatkan suntikan dana sebesar USD 1,1 Miliar dari Alibaba. Tokopedia merupakan salah satu startup yang masuk dalam golongan unicorn. Suatu startup dapat masuk dalam kategori unicorn jika nilai valuasinya lebih dari USD 1 Miliar. Tokopedia merupakan rajanya marketplace di Indonesia. Tokopedia ini merupakan bisnis yang paling aman serta mempunyai banyak kemudahan dalam pelayanan serta fiturnya yang bermacam manfaat dan mudah dapat diakses dan dalam setiap bisnis pasti memiliki pesaing, begitu juga dengan bisnis online.

\section{E. DISKUSI}

Saya bersama teman kuliah saya yang bernama Imam Saputa mendiskusiakn tentang materi Tokopedia ini. Hasil diskusi dari materi ini adalah menurut dia Tokopedia adalah perusahaan ecommerce terbesar di Indonesia saat ini. Tokopedia merupakan startup buatan dalam negeri yang didirikan oleh pemuda kreatif Indonesia. Tokopeida merupakan satu dari 4 Unicorn di Indonesia. Tokopedia banyak mendapat investasi dari perusahaan ecommerce asal China yaitu Alibaba yang membuat perusahaan 
ini menjadi yang terbesar di Indonesia. Aplikasi Tokopedia bisa didownload di google playstore maupun di appstore. Tokopedia merupakan situs jual beli online yang aman dan memiliki banyak fitur didalamnya. Tokopedia sangat familiar di Indonesia, apabila orang ditanya perusahaan ecommerce yang paling sering dikunjungi salah satunya adalah tokopedia. Menurut dia berbelanja online yang aman dan memiliki banyak fitur didalamnya Tokopedia adalah tempatnya. Karena berbelanja online saat ini merupakan hobi baru masyarakat Indonesia, apalagi untuk generasi millenial seperti kita ini. Mau belanja online ya di Tokopedia tempatnya.

\section{F. REFERENCE}

[1] O. M. Febriani and A. S. Putra, "Sistem Informasi Monitoring Inventori Barang Pada Balai Riset Standardisasi Industri Bandar Lampung," J. Inform., vol. 13, no. 1, pp. 90-98, 2014.

[2] A. S. Putra, "Paperplain: Execution Fundamental Create Application With Borland Delphi 7.0 University Of Mitra Indonesia," 2018.

[3] A. S. Putra, "2018 Artikel Struktur Data, Audit Dan Jaringan Komputer," 2018.
A. S. Putra, "ALIAS MANAGER USED IN DATABASE DESKTOP STUDI CASE DB DEMOS."

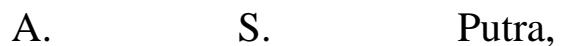
"COMPREHENSIVE SET OF PROFESSIONAL FOR DISTRIBUTE COMPUTING."

[6] A. S. Putra, "DATA ORIENTED RECOGNITION IN BORLAND DELPHI 7.0.”

[7] A. S. Putra, "EMBARCADERO DELPHI XE 2 IN GPUPOWERED FIREMONKEY APPLICATION." 
[8] A. S. Putra, "HAK ATAS KEKAYAAN INTELEKTUAL DALAM DUNIA TEKNOLOGY BERBASIS REVOLUSI INDUSTRI 4.0."

[9] A. S. Putra, "IMPLEMENTASI PERATURAN PERUNDANGAN UU. NO 31 TAHUN 2000 TENTANG DESAIN INDUSTRI BERBASIS INFORMATION TECHNOLOGY."

$\begin{array}{lr}\text { A. S. } & \text { Putra, } \\ \text { "IMPLEMENTATION } & \text { OF } \\ \text { PARADOX DBASE." } & \end{array}$

A. $\mathrm{S}$. Putra, "IMPLEMENTATION OF TRADE SECRET CASE STUDY SAMSUNG MOBILE PHONE."

[12] A. S. Putra, "IMPLEMENTATION PATENT FOR APPLICATION WEB BASED CASE STUDI WWW. PUBLIKLAMPUNG. COM."

A. S. Putra, "IMPLEMENTATION SYSTEM FIRST TO INVENT IN DIGITALLY INDUSTRY."

[14] A. S. Putra, "MANUAL REPORT \& INTEGRATED DEVELOPMENT

ENVIRONMENT BORLAND DELPHI 7.0."

[15] A. S. Putra, "PATENT AS RELEVAN SUPPORT RESEARCH."

[16] A. S. Putra, "PATENT FOR RESEARCH STUDY CASE OF APPLE. Inc."

[17] A. S. Putra, "PATENT PROTECTION FOR APPLICATION INVENT."

[18] A. S. Putra, "QUICK REPORT
IN PROGRAMMING."

A. S. Putra, "REVIEW CIRCUIT LAYOUT COMPONENT

REQUIREMENT ON ASUS NOTEBOOK."

[20] A. S. Putra, "REVIEW TRADEMARK PATENT FOR INDUSTRIAL TECHNOLOGY BASED 4.0."

[21] A. S. Putra, "TOOLBAR COMPONENT PALLETTE IN OBJECT ORIENTED PROGRAMMING."

[22] A. S. Putra, "WORKING DIRECTORY SET FOR PARADOX 7."

[23] A. S. Putra, "ZQUERY CONNECTION

IMPLEMENTED

PROGRAMMING STUDI CASE PT. BANK BCA Tbk."

[24] A. S. Putra, D. R. Aryanti, and I. Hartati, "Metode SAW (Simple Additive Weighting) sebagai Sistem Pendukung Keputusan Guru Berprestasi (Studi Kasus: SMK Global Surya)," in Prosiding Seminar Nasional Darmajaya, 2018, vol. 1, no. 1, pp. 85-97.

[25] A. S. Putra and O. M. Febriani, "Knowledge Management Online Application in PDAM Lampung Province," in Prosiding International conference on Information Technology and Business (ICITB), 2018, pp. 181-187.

[26] A. S. Putra, O. M. Febriani, and B. Bachry, "Implementasi Genetic Fuzzy System Untuk Mengidentifikasi Hasil Curian Kendaraan Bermotor Di Polda 
Lampung," SIMADA (Jurnal Sist. Inf. dan Manaj. Basis Data), vol. 1, no. 1, pp. 21-30, 2018.

[27] A. S. Putra, H. Sukri, and K. Zuhri, "Sistem Monitoring Realtime Jaringan Irigasi Desa (JIDES) Dengan Konsep Jaringan Sensor Nirkabel," IJEIS (Indonesian J. Electron. Instrum. Syst., vol. 8, no. 2, pp. 221-232.

[28] D. P. Sari, O. M. Febriani, and A. S. Putra, "Perancangan Sistem Informasi SDM Berprestasi pada SD Global Surya," in Prosiding Seminar Nasional Darmajaya, 2018, vol. 1, no. 1, pp. 289-294. 